\title{
Cerebellar Involvement in Response Reassignment Rather Than Attention
}

\author{
Amanda Bischoff-Grethe, ${ }^{1}$ Richard B. Ivry, ${ }^{2}$ and Scott T. Grafton ${ }^{1}$ \\ ${ }^{1}$ Center for Cognitive Neuroscience and the Department of Psychological and Brain Sciences, Dartmouth College, \\ Hanover, New Hampshire 03755, and 2Department of Psychology, University of California, Berkeley, Berkeley, \\ California 94720-1650
}

\begin{abstract}
A number of functional hypotheses have recently been advanced to account for how the cerebellum may contribute to cognition. Neuropsychological studies suggest the cerebellum is involved in switching attentional set. We present evidence that fails to support this hypothesis. Rather, we propose that in such tasks, the cerebellum is involved with the remapping of response alternatives to different types of stimuli. In our experiment, participants fixated on the center of a screen onto which a random presentation of four visual stimuli was presented. The stimuli were grouped along two dimensions (color: red square or blue square; shape: white circle or white triangle). Participants were instructed to respond with a button press only to presented stimuli for a particular dimension (e.g., red squares), to switch between two dimensions (where the target on the
\end{abstract}

attended dimension served both as a signal for a response and as an indicator to shift attention to the other dimension), or to switch attention between two dimensions but make an overt response only to targets on one of the dimensions. Using functional imaging, we identify areas of lateral cerebellar cortex that are recruited when subjects must reassign motor responses to different stimuli. Furthermore, we demonstrate that switching of attention between dimensions without a motor response does not produce stronger activation within the cerebellum compared with conditions involving response and attention to a single dimension. These results suggest the cerebellum is involved in response reassignment.

Key words: functional imaging; cerebellum; attention; sensorimotor; response reassignment; cognition
Cerebellar function is associated with sensorimotor coordination, adaptation, and associative learning (Albus, 1971; Brooks and Thach, 1981; Ito, 1984). Human lesion and functional imaging studies (Ivry and Keele, 1989; Petersen et al., 1989; Fiez et al., 1996; Gao et al., 1996; Desmond and Fiez, 1998) suggest that the functional domain of the cerebellum is not limited to motor control. Given the anatomical connections between the neocerebellum and association cortical areas, including prefrontal cortex (Schmahmann and Pandya, 1997a; Middleton and Strick, 2000, 2001), various hypotheses have been proposed concerning how the cerebellum may be part of a neural circuit involved in executive control.

One influential model proposes that the cerebellum is involved in coordinating rapid shifts of attention, similar to the way this structure contributes to the coordination of rapid movements. Working with children and young adults whose cerebellar pathology was caused by infantile autism or neurological damage (Akshoomoff and Courchesne, 1992), Courchesne et al. (1994) observed a deficit on tasks requiring the rapid alternation of attention between different stimulus dimensions. Imaging data in normal subjects revealed enhanced activity in lateral cerebellar cortex when subjects paid attention to specific sensory information (Allen et al., 1997) or switched attention between different

\footnotetext{
Received Aug. 15, 2001; revised Oct. 17, 2001; accepted Nov. 1, 2001.

This work was supported by Public Health Service Grant NS33504 and the James $\mathrm{S}$. McDonnell Foundation. The data reported in this experiment have been deposited at the fMRI Data Center with accession number 2-2001-1127J (http:// www.fmridc.org/database/?accession=2-2001-1127J).

Correspondence should be addressed to Scott T. Grafton, Center for Cognitive Neuroscience, Dartmouth College, 6162 Moore Hall, Hanover, NH 03755. E-mail: Scott.T.Grafton@dartmouth.edu.

Copyright (ㄷ) 2002 Society for Neuroscience $0270-6474 / 02 / 220546-08 \$ 15.00 / 0$
}

visual features (Le et al., 1998). Localization within the cerebellum was lateral to the parasagittal areas and to vermal areas associated with movements.

Ravizza and Ivry (2001) have recently challenged the attention switching account of cerebellar function. Patients with either Parkinson's disease or cerebellar pathology exhibited similar deficits on the attention shifting task introduced by Courchesne et al. (1994). The lack of specificity suggests that this impairment may be a general feature of neurological damage. More importantly, when the task was modified so that overt responses were only required to targets on one dimension, the deficit in the cerebellar group was largely attenuated, even though the attention switching requirements remained the same. Impairments in coordinating rapid shifts of attention after cerebellar damage may thus be related to the requirement in the attention shifting condition to alter the task-relevant stimulus-response mapping, what we call response reassignment. Interestingly, the Parkinson patients continued to exhibit an attention shifting deficit under the reduced movement condition, consistent with a role for the basal ganglia in attention shifting (Brown and Marsden, 1988; Hayes et al., 1998; Rogers et al., 1998).

In this report we test this hypothesis using functional magnetic resonance imaging (fMRI). Central to our experiment is the idea that attention shifting tasks involve two component processes. One process entails the focus of attention, establishing which stimulus dimension is relevant for responding. The second process entails the link between target stimuli on the selected dimension and response processes. In most attention shifting tasks, these two processes are confounded. However, they can be dissociated. Response reassignment requires attentional switching, whereas attentional switching can occur without motor intention. 


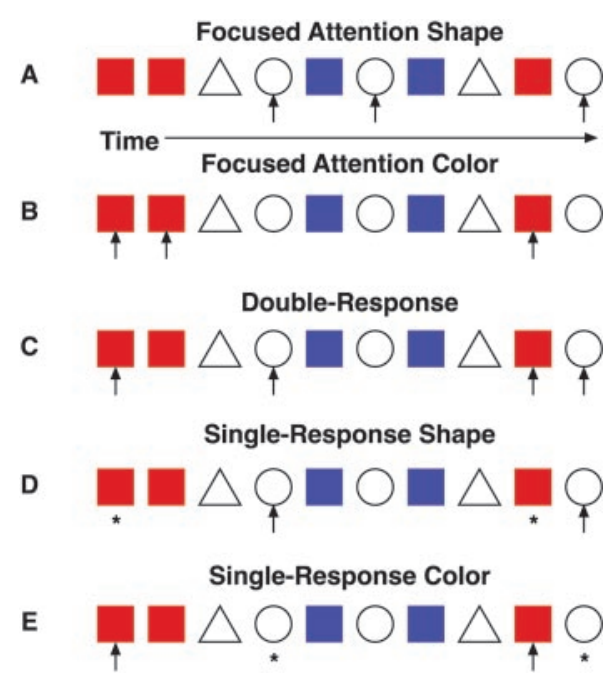

Figure 1. Examples of stimulus sequences and responses for each condition. Red squares and white circles were the targets, and blue squares and white triangles were the distractors. Arrows indicate where an attention shift and/or key press were required. Asterisks indicate that only an attention shift was required. The five conditions were: $A$, focused attention shape; $B$, focused attention color; $C$, double-response; $D$, singleresponse shape; and $E$, single-response color.

We hypothesize that separate neural representations exist to handle different categories of switching. Of critical interest, we show that switching of attention between dimensions without a motor response does not produce stronger activation within the cerebellum compared with a focused attention condition. These results argue against a role for the cerebellum in attentional switching; rather the cerebellum appears to be engaged during response reassignment.

\section{MATERIALS AND METHODS}

Experimental design. Ten right-handed participants (seven male and three female) aged 21-47 years (average age, 29.9 years) gave written informed consent. Four visual stimuli (red square, blue square, white circle, and white triangle) were individually presented in random order for 84 trials. The red square and the white circle were designated as targets; each target was presented $17 \%$ of the time. The blue square and white triangle were designated as distractors, and each occurred $33 \%$ of the time. Stimulus duration was $100 \mathrm{msec}$, and the stimulus onset asynchrony (SOA) varied randomly from 450 to $1450 \mathrm{msec}$. Participants were given a button box and were instructed to press a button using the index finger of the right hand when specific targets appeared in the center of the screen. Response latency was recorded on-line with an optically encoding system compatible with fMRI.

Five separate attention conditions were presented to each subject (Fig. 1). Two were focused attention conditions, where participants were required to respond to all occurrences of the red square (focused attention color) while ignoring all other stimuli or to respond to all occurrences of the white circle (focused attention shape). In the double response condition, participants were instructed to alternate between targets by responding to a target defined by one dimension (e.g., color), then to a target on the other dimension (e.g., shape) and so on. In this condition, targets not only served as stimuli requiring a response but also served as a cue to shift attention between the two dimensions. The final two conditions were single response conditions. Here participants shifted attention between targets as in the double response condition, but were to respond to targets on only one dimension (e.g., single response color or single response shape) throughout the condition. All conditions had the same number of target stimuli ( $\sim 14$ per block), but the single response conditions had half as many overt responses as the double response and focused attention conditions.

Participants were given one or more practice sessions on each condition to ensure they were comfortable with each task before scanning. The order of condition presentation was counterbalanced across participants.
Each functional imaging session consisted of one condition plus rest, and each subject performed all five conditions, leading to a total of five imaging sessions per subject.

MRI. Five fMRI sessions of 60 scans each were obtained, with one session per condition. Functional MRI was performed with gradientrecalled echoplanar imaging (reaction time, $2000 \mathrm{msec}$; echo time, 35 msec; flip angle, $90^{\circ}$; $64 \times 64$ matrix; $275.5 \mathrm{~mm}$ contiguous axial slices) on a GE 1.5 T scanner (Kwong et al., 1992; Ogawa et al., 1992). Coplanar structural T1-weighted, and high-resolution MRIs were obtained for subsequent spatial normalization.

Statistical analysis. The data were analyzed using Statistical Parametric Mapping (SPM99; Wellcome Department of Cognitive Neurology, London, UK) (Friston et al., 1995). Motion correction to the first functional scan was performed within subject using a six-parameter rigid-body transformation. The mean of the motion-corrected images was first coregistered to the individual's high-resolution MRI using mutual information, followed by coregistration of the structural MRI to the functional images using a 12-parameter affine transformation. The images were then spatially normalized to the Montreal Neurologic Institute (MNI) template (Talairach and Tournoux, 1988) by applying a 12 parameter affine transformation followed by a nonlinear warping using basis functions (Ashburner and Friston, 1999). The spatially normalized scans were then smoothed with a $6 \mathrm{~mm}$ isotropic Gaussian kernel to accommodate anatomical differences across participants. The data were analyzed using a random-effects model to make statistical inferences (Friston et al., 1999). The two focused attention tasks were combined into the FOCUS condition for activation analyses; similarly, the single response tasks were combined to form the SINGLE condition. The DOUBLE condition referenced the double response task.

\section{RESULTS}

Functional MRI data were collected during subjects' performance of each condition, and the analyses were designed to identify areas of activation related to movement, shifts of attention, and shifts of attention and stimulus-response mappings. All task conditions averaged 14 targets, but the number of motor responses differed; the FOCUS and DOUBLE conditions required motor responses to all targets, whereas the SINGLE conditions required responses to targets on only one dimension, or seven targets per session. The task conditions were characterized by one or more of the following attributes: attentional switching (switching attentional set between the two dimensions); response reassignment (switching motor set between the target stimuli requiring an overt response); and total movements performed (Table 1). The FOCUS conditions did not involve attention switching or response reassignment, whereas the DOUBLE condition involved both. The SINGLE conditions only involved switching attention because the motor response was always to the same target.

Subjects performed all conditions with $>90 \%$ accuracy (Table 2). Paired-sample $t$ tests of response times (RTs) showed that the RTs were faster for the FOCUS condition compared with both the DOUBLE $(t(9)=3.25 ; p=0.005)$ and SINGLE $(t(9)=$ $-1.707 ; p=0.061)$ conditions. Moreover, the DOUBLE and SINGLE conditions were not statistically different $(t(9)=0.188$; $p=0.855)$. Mean RTs for these conditions differed by only 3 msec. These findings are consistent with the idea that the two divided attention conditions were more difficult because of the demands to shift attention between the two dimensions. The RTs indicate that the DOUBLE and SINGLE conditions were of comparable difficulty.

Linear contrasts between different tasks were used to examine differences of the functional attributes. Using a threshold for significance of $p<0.01$ (uncorrected), the six possible contrasts were defined pairwise. Of the contrasts defined, four permitted separation of activations related to movement (FOCUS $>$ SINGLE, DOUBLE > SINGLE), attentional switching (SINGLE $>$ FOCUS, DOUBLE $>$ FOCUS), and response reassign- 
Table 1. The relationships of tasks and task comparisons to attentional switching, response reassignment, and movement

\begin{tabular}{|c|c|c|c|c|c|c|}
\hline & \multicolumn{3}{|l|}{ Behavior } & \multicolumn{3}{|c|}{ Lateral cerebellum } \\
\hline & $\begin{array}{l}\text { Attention } \\
\text { switch }\end{array}$ & $\begin{array}{l}\text { Response } \\
\text { reassignment }\end{array}$ & $\begin{array}{l}\Delta \text { Motor } \\
\text { response }\end{array}$ & $\begin{array}{l}\text { Left lobule VI } \\
(-22,-68,-30)\end{array}$ & $\begin{array}{l}\text { Right lobule VI } \\
(22,-66,-22)\end{array}$ & $\begin{array}{l}\text { Right lobule VI } \\
(22,-44,-24)\end{array}$ \\
\hline \multicolumn{7}{|l|}{ Contrasts } \\
\hline DOUBLE > FOCUS & Yes & Yes & 0 & Yes & Yes & No \\
\hline SINGLE > FOCUS & Yes & No & $0.5 \times$ & No & No & No \\
\hline DOUBLE $>$ SINGLE & No & Yes & $2 \times$ & Yes & Yes & No \\
\hline SINGLE $>$ DOUBLE & No & No & $0.5 \times$ & No & No & No \\
\hline FOCUS > SINGLE & No & No & $2 \times$ & No & No & Yes \\
\hline FOCUS $>$ DOUBLE & No & No & 0 & No & No & No \\
\hline
\end{tabular}

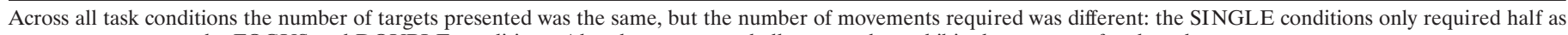
many movements as the FOCUS and DOUBLE conditions. Also shown are cerebellar areas that exhibited a response for the relevant contrasts.

\begin{tabular}{|c|c|c|c|}
\hline & $\begin{array}{l}\text { Reaction } \\
\text { time (msec) }\end{array}$ & $\begin{array}{l}\% \text { Short } \\
\text { ITI hits }\end{array}$ & $\begin{array}{l}\% \text { Long } \\
\text { ITI hits }\end{array}$ \\
\hline Double & 555.81 & 95.71 & 97 \\
\hline Focused color & 527.25 & 96 & 93.33 \\
\hline Focused shape & 527.10 & 89 & 95.67 \\
\hline Single color & 553.44 & 93.75 & 92.22 \\
\hline Single shape & 557.66 & 100 & 100 \\
\hline
\end{tabular}

A short ITI is described as two successive targets requiring a response appearing $<2.5 \mathrm{sec}$ apart. Thus, a long ITI is described as two successive targets appearing $>2.5 \mathrm{sec}$ apart.

ment (DOUBLE > SINGLE). Table 3 lists cortical and cerebellar regions activated using these different contrasts of interest.

We first localized the relative activations within cerebellum related to the three attributes of the task. According to our hypothesis, the cerebellum should not show activation related to the demands to shift attention, but rather would be related to the motor demands of the task or response reassignment. Contrasts that would reveal movement related activity compared the DOUBLE or FOCUS tasks to the SINGLE tasks. These contrasts revealed activation within right lobule IV and right lobule VI (Fig. 2). The reverse comparison of the SINGLE condition to the DOUBLE and FOCUS tasks revealed no cerebellar activation in these regions; an expected result as the SINGLE condition has half as many motor responses. These results are consistent with other studies indicating motor activation within parasagittal cerebellum (Allen et al., 1997; Grodd et al., 2001).

We next examined contrasts that would test the hypothesis that cerebellar activation is related to task switching. The first contrast compares the DOUBLE condition, where shifting is present, to the FOCUS condition, where no shifting occurs. Consistent with previous reports (Allen et al., 1997; Le et al., 1998), activation was observed within left lobule IV, left lobule VI, and right lobule VI. However, this contrast involves both attention shifting and response reassignment. To isolate attention shifting, we used the SINGLE $>$ FOCUS contrast because only attention switching is required in the SINGLE condition. Here we failed to detect any difference in cerebellar activation. This argues strongly against cerebellar involvement in attentional shifting, but lends credence to a role for this structure in response reassignment. It is likely that the cerebellar activation seen when comparing the DOU-
BLE condition to the FOCUS condition is also attributable to response reassignment.

To confirm this result, we further examined the adjusted blood-oxygen level-dependent (BOLD) response for three of the activated cerebellar foci, averaged across subjects (Fig. 3). We found increased activation related to the DOUBLE condition in all three foci, decreased activation related to the SINGLE condition, and a decrease within two of the foci for the FOCUS condition. The evidence suggests these foci are involved with response reassignment, because the SINGLE condition did not increase activation. Furthermore, the increased activation for both the DOUBLE and FOCUS conditions within R lobule VI suggests this area may play a role in both response reassignment and motor response.

Attentional shifting was associated with a distributed pattern of cortical activation (Fig. 4). The DOUBLE $>$ FOCUS and SINGLE > FOCUS contrasts activated several cortical attention areas, including left middle frontal gyrus (supplementary motor area), left anterior cingulate, and left precuneus. In both of these comparisons, the ability to shift attention was necessary, although only the DOUBLE > FOCUS also requires response reassignment. We did not observe any foci within the basal ganglia that were active in the two conditions requiring attentional shifts.

As previously described in Table 1, movement-related areas are expected to be most commonly seen with the FOCUS $>$ SINGLE contrast, because the FOCUS condition has more movements than the SINGLE condition. This contrast activated left precentral gyrus (motor cortex) and left middle frontal gyrus.

\section{DISCUSSION}

Various lines of evidence have linked the cerebellum to higherlevel, executive functions. However, characterizing the functional contribution of the cerebellum has remained elusive. Visuospatial attention studies using positron emission tomography (Corbetta et al., 1993) or event-related evoked potentials (Yamaguchi et al., 1998) have reported cerebellar activity in relation to motor aspects of the tasks. Our results are in concurrence with these studies, although we have proposed that the cerebellum contributes to a specific process involved in moving in cognitive tasks. We found right lateral cerebellum activation related to response reassignment rather than attentional switching. Activation was highest in the DOUBLE condition when both attention and response reassignment were required. In contrast, no activation was found in the cerebellum when we compared the SINGLE condition with the focused attention conditions. In the SINGLE condition, the participants were still required to shift attention 


\begin{tabular}{|c|c|c|c|c|c|}
\hline \multirow{2}{*}{$\frac{\text { Region }}{\text { DOUBLE }>\text { FOCUS }}$} & \multirow[t]{2}{*}{ Cluster (voxels) } & \multicolumn{3}{|c|}{ MNI coordinates $(x, y, z)$} & \multirow[t]{2}{*}{$Z$ score } \\
\hline & & & & & \\
\hline Left lobule IV & 64 & -6 & -44 & -22 & 4.15 \\
\hline Left lobule VI & 43 & -22 & -68 & -30 & 5.79 \\
\hline Right lobule VI & 22 & 12 & -74 & -26 & 4.57 \\
\hline Right lobule VI & 47 & 24 & -66 & -20 & 4.13 \\
\hline Left anterior cingulate (24) & 511 & -6 & 20 & 38 & 6.15 \\
\hline Left medial frontal gyrus (6) & & -2 & -16 & 60 & 4.80 \\
\hline Right middle frontal gyrus (6) & 81 & 36 & -4 & 52 & 4.31 \\
\hline Right inferior frontal gyrus (44) & 132 & 46 & 8 & 22 & 4.09 \\
\hline Left inferior frontal gyrus (47) & 125 & -40 & 14 & -6 & 5.71 \\
\hline Right inferior frontal gyrus (47) & 40 & 38 & 20 & -6 & 4.11 \\
\hline Left precuneus (7) & 81 & -10 & -72 & 42 & 4.81 \\
\hline Right precuneus (7) & 472 & 10 & -52 & 58 & 6.33 \\
\hline Left inferior parietal lobule (40) & 54 & -42 & -48 & 46 & 4.70 \\
\hline \multicolumn{6}{|l|}{ DOUBLE $>$ SINGLE } \\
\hline Left lobule VI & 23 & -24 & -50 & -22 & 3.92 \\
\hline Left vermis IV & 139 & -6 & -44 & -22 & 4.13 \\
\hline Right lobule IV & & 4 & -46 & -14 & 3.93 \\
\hline Right lobule VI & 245 & 22 & -66 & -22 & 4.49 \\
\hline Right posterior thalamus & 53 & 8 & -26 & 4 & 5.42 \\
\hline Right medial GP & 41 & 20 & -10 & -2 & 4.32 \\
\hline Left putamen & 34 & -30 & 0 & -8 & 4.00 \\
\hline Left central gyrus (32) & 60 & -12 & 2 & 46 & 4.08 \\
\hline Left medial frontal gyrus (32) & 45 & -6 & 20 & 38 & 3.78 \\
\hline Right central gyrus (32) & 20 & 10 & 24 & 34 & 3.42 \\
\hline Left postcentral gyrus (4) & 81 & -36 & -34 & 54 & 4.60 \\
\hline Left middle frontal gyrus (6) & 120 & -36 & -4 & 54 & 5.22 \\
\hline Left medial frontal gyrus (6) & 88 & -16 & -8 & 62 & 7.42 \\
\hline Left medial frontal gyrus ( 6 ) & 75 & 0 & -18 & 58 & 4.91 \\
\hline Right middle frontal gyrus $(6)$ & 317 & 24 & 4 & 50 & 5.61 \\
\hline Right inferior frontal gyrus (44) & 233 & 44 & 10 & 20 & 5.41 \\
\hline Left paracentral lobule $(5 / 7)$ & 56 & -18 & -50 & 62 & 5.25 \\
\hline Left fusiform (19) & 46 & -26 & -76 & -20 & 4.21 \\
\hline Right superior temporal gyrus (38) & 322 & 44 & 0 & -10 & 5.16 \\
\hline Left superior temporal gyrus (22) & 67 & -46 & -30 & 14 & 5.55 \\
\hline Left superior temporal gyrus (22) & 25 & -50 & -2 & 0 & 5.54 \\
\hline \multicolumn{6}{|l|}{ SINGLE $>$ FOCUS } \\
\hline Left anterior cingulate (32) & 75 & -2 & 18 & 38 & 4.41 \\
\hline Right precentral gyrus (6) & 75 & 38 & -4 & 46 & 3.92 \\
\hline Right inferior frontal gyrus (47) & 72 & 40 & 28 & -2 & 6.37 \\
\hline Right precuneus (7) & 252 & 6 & -70 & 40 & 5.61 \\
\hline Left inferior parietal lobule (40) & 85 & -56 & -38 & 32 & 4.63 \\
\hline \multicolumn{6}{|l|}{ FOCUS $>$ SINGLE } \\
\hline Left lobule V & 21 & -14 & -46 & -12 & 5.60 \\
\hline Right lobule VI & 63 & 22 & -44 & -24 & 4.21 \\
\hline Left ventral thalamus & 35 & -6 & -10 & 6 & 5.70 \\
\hline Left precentral gyrus (4) & 91 & -30 & -28 & 42 & 5.11 \\
\hline Right precentral gyrus (4) & 63 & 36 & -24 & 50 & 5.51 \\
\hline Right cingulate gyrus (23) & 120 & 16 & -60 & 18 & 4.21 \\
\hline Right cingulate gyrus (30) & 75 & 20 & -50 & 2 & 4.63 \\
\hline Left cingulate gyrus (24) & 35 & -10 & -14 & 44 & 5.24 \\
\hline Right medial frontal gyrus (32) & 51 & 18 & 22 & 40 & 4.17 \\
\hline Left medial frontal gyrus (6) & 28 & -10 & -14 & 58 & 4.75 \\
\hline Right middle frontal gyrus (6) & 45 & 24 & -10 & 56 & 6.66 \\
\hline Left paracentral lobule (5) & 107 & -8 & -36 & 52 & 4.19 \\
\hline Right postcentral gyrus (7) & 111 & 30 & -44 & 62 & 6.99 \\
\hline Left parieto-occipital sulcus (31) & 20 & -12 & -70 & 14 & 3.60 \\
\hline Left lingual gyrus (18) & 231 & -6 & -80 & -4 & 5.32 \\
\hline Left cuneus (18) & 31 & -10 & -76 & 22 & 3.62 \\
\hline Right hippocampus/27 & 51 & 20 & -32 & -8 & 5.81 \\
\hline Left middle temporal gyrus $(21 / 37)$ & 39 & -50 & -58 & -2 & 6.76 \\
\hline Left superior temporal gyrus (22) & 21 & -50 & -2 & -8 & 3.99 \\
\hline Right superior temporal gyrus (22) & 104 & 40 & -54 & 16 & 5.49 \\
\hline Left superior temporal gyrus (39) & 29 & -48 & -60 & 28 & 3.94 \\
\hline Left transverse temporal gyri (41) & 313 & -44 & -26 & 10 & 5.53 \\
\hline Right transverse temporal gyri (42) & 340 & 46 & -28 & 14 & 6.48 \\
\hline
\end{tabular}

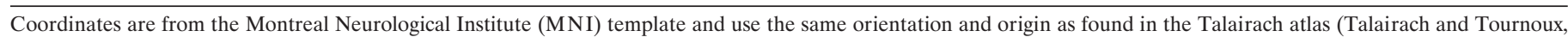
1988). The table shows at most local maxima $>8.00 \mathrm{~mm}$ apart per cluster $(k \geq 20)$. 


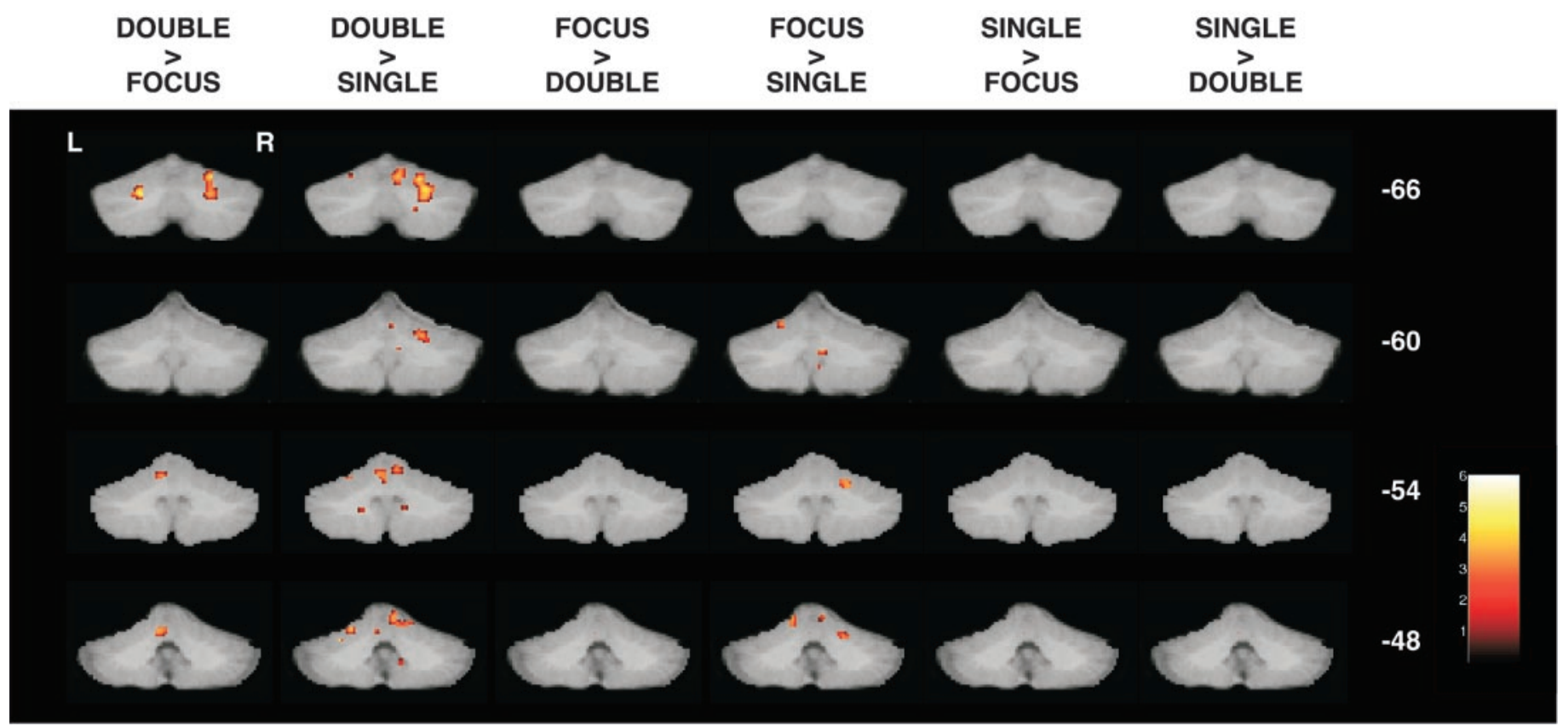

Figure 2. Statistical parametric maps showing cerebellar regions correlating with the different contrasts applied. Coronal slices (Talairach coordinates: $Y=-66, Y=-60, Y=-54$, and $Y=-48$ ) indicate areas associated with the interactions (DOUBLE $>$ FOCUS, DOUBLE $>$ SINGLE, FOCUS $>$ DOUBLE, FOCUS $>$ SINGLE, SINGLE $>$ FOCUS, and SINGLE $>$ DOUBLE).

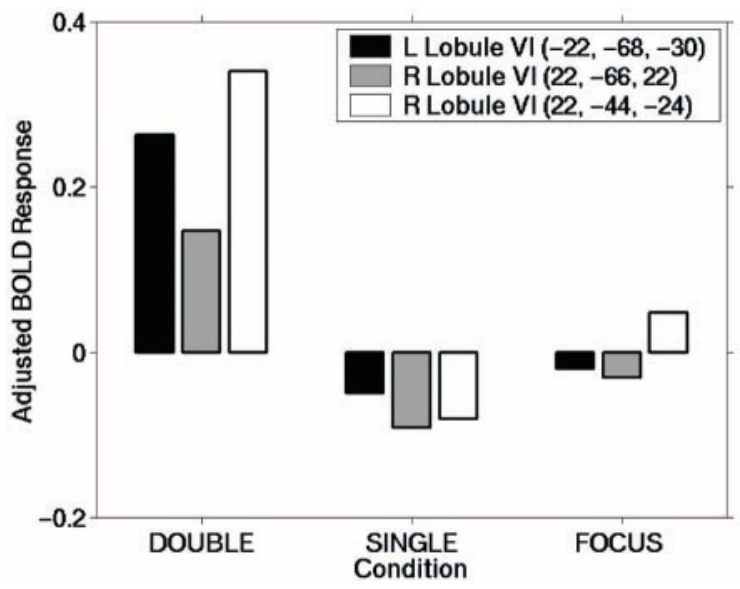

Figure 3. Graph illustrating adjusted BOLD response for relevant cerebellar foci across condition types. L lobule VI $(-22,-68,-30)$ shows an increased activation for the DOUBLE condition, whereas the SINGLE and FOCUS conditions show decreased activation. R lobule VI $(22,-66$, -22) shows increased activation for the DOUBLE condition and decreased activation for SINGLE and FOCUS. R lobule VI $(22,-44,-24)$ shows an increase in activation for DOUBLE and FOCUS, but a decrease in activation for the SINGLE condition. Overall, this suggests cerebellar involvement in these foci is attributable to response reassignment rather than facilitating attention switching.

between the two dimensions; however, response reassignment was no longer required because overt responses were only required to one of the two target stimuli. We also found cerebellar activation related to motor performance. Thus, cerebellar activation was related to both the movement demands and higher-level aspects of visuomotor control such as the establishment of stimulus-response associations. Such activation was not present when attentional shifting was isolated from response reassignment.
Courchesne et al. (1994) reported that cerebellar patients had difficulties in shifting attention between stimuli when the intertarget intervals (ITIs) were short $(<2.5 \mathrm{sec})$. This impairment is observed on tasks in which attention must shift between different sensory channels or between different dimensions of a single sensory channel. Cerebellar patient performance was equivalent to control subjects for long ITIs $(2.5-30 \mathrm{sec})$. This suggested that the cerebellum was needed to ensure that the shifts occurred rapidly once a new focus of attention was specified. Previous imaging studies (Allen et al., 1997; Le et al., 1998) have reported greater activation in the right lateral cerebellum during conditions involving attention shifting compared with focused attention conditions. We observed similar results slightly medial to this region during our DOUBLE condition in which responses were required to targets on both dimensions. Given that no increase was found in the SINGLE condition, however, it is likely that the activation reflects response reassignment. Furthermore, our response reassignment site is lateral to the foci activated within the contrasts comparing the FOCUS and DOUBLE conditions with the SINGLE condition. The area activated by those contrasts is likely responsible for movement performance. The fact that cerebellar patients struggled with rapid attention shifts (Courchesne et al., 1994) suggests the difficulty lay in shifting between different sensorimotor sets rather than attention itself.

The Wisconsin Card Sort Test (WCST) is a well known technique for studying the prefrontal cortex, and imaging studies using this task have identified activation within right lateral cerebellum (Berman et al., 1995; Nagahama et al., 1996). However, Daum et al. (1993) noted that the impairment seen in cerebellar patients performing the WCST occurs only when the cerebellar degeneration extends to brainstem structures. Mangels et al. (1998) found that whereas cerebellar and prefrontal patients performed similarly on neuropsychological tests assessing initiation, fluency, and perseveration, cerebellar patients demonstrated reduced processing speed in the presence of preserved working 


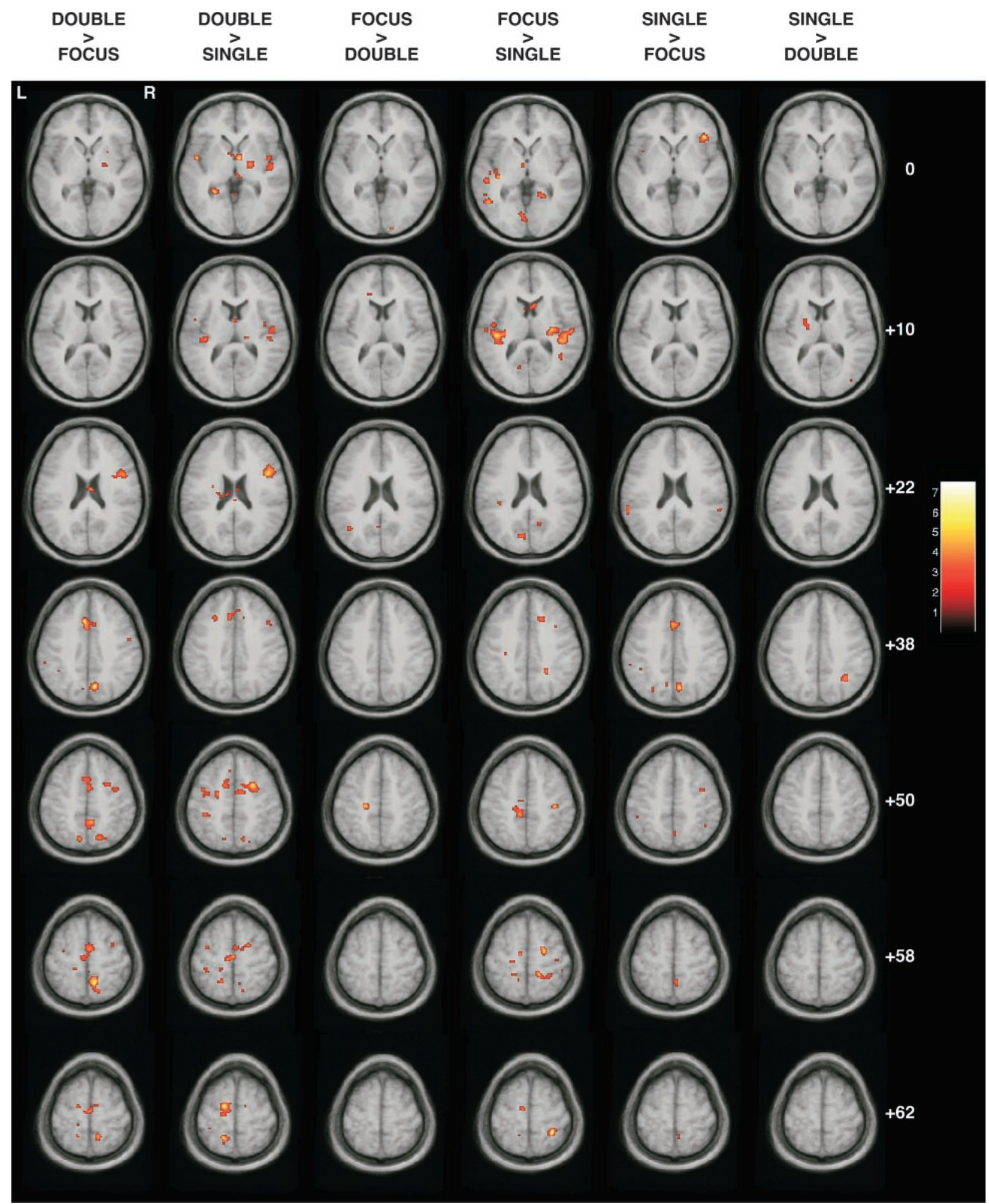

Figure 4. Statistical parametric maps showing cortical regions that correlated with the different contrasts applied. Axial slices (Talairach coordinates: $Z=0, Z=+10, Z=+22, Z=+38, Z=+50, Z=+58$, and $Z=+62$ ) illustrate activations associated with the interactions (DOUBLE $>$ FOCUS, DOUBLE $>$ SINGLE, FOCUS $>$ DOUBLE, FOCUS $>$ SINGLE, SINGLE > FOCUS, and SINGLE > DOUBLE).

memory function. Attention shifting tasks involve multiple executive processes. It is therefore not surprising that diverse patient populations are impaired on these tasks and that activation observed in imaging studies is widespread and includes the cerebellum. The involvement of the cerebellum, though, should be con- sidered within a hierarchy of processes needed to accomplish the task. Our evidence argues against involvement in assisting attentional shift per se, but rather focuses on the motor component involved with an attention shifting task.

Recent computational theories of motor control have articu- 
lated a cerebellar architecture in which an internal model is constructed that consists of multiple "modules" that link forward and inverse models (Wolpert and Kawato, 1998; Kawato, 1999; Wolpert and Ghahramani, 2000). These modules allow for the simultaneous prediction of multiple inverse models and rely on contextual information to provide a framework for the appropriate module to produce an action. Our results support this modular view of cerebellar function; the DOUBLE condition involves two different contextual situations (respond to a red square or respond to a white circle) that might be represented by two different stimulus-response modules within the cerebellum. The SINGLE and FOCUS conditions involve responding to only one target type, thus lacking the necessity of switching between contextual representations (and therefore modules). Furthermore, the "activation" of these modules likely relies upon cortical information, such as that seen in supplementary motor area and the anterior cingulate (Doya, 1999). Both areas were strongly active in the contrasts comparing the DOUBLE condition with the FOCUS and SINGLE conditions.

The notion that the cerebellum is associated with contextresponse linkage has been discussed by Thach (1997). Anatomical studies suggest cerebellar output is divided into multiple channels (Middleton and Strick, 1997, 2000, 2001). Lobule VI, where our response-reassignment activation occurred, receives afferents from the motor cortex and premotor cortex, as well as a more limited input from the parietal lobe (Schmahmann and Pandya, 1997b). This region of the neocerebellar cortex projects to the dentate. Progressing from dorsal to ventral within the dentate, the cortical targets shift from motor (motor and premotor cortex) to cognitive (prefrontal cortex). Our activation locus may conceptually lie between the cognitive and motor channels, providing the mechanisms of linking the cognitive context with the appropriate motor set represented in premotor cortex (Kurata and Wise, 1988).

Our results revealed cerebral cortical activation related to attention. Comparisons of the DOUBLE and SINGLE conditions with the FOCUS conditions showed activation within left middle frontal gyrus, left anterior cingulate, left precuneus, and left inferior parietal lobule. These areas indicate that higher order processing of the attentional shifting did take place. We believe the involvement of the cerebellum was on a lower level, because its activation was related to different stimulus-response pairs in the DOUBLE condition. This motor processing would rely on cues from further up the hierarchy to dictate the appropriate response for the presented stimulus. Previous imaging studies of attention set-shifting have indicated activation within the prefrontal cortex, typically in the dorsolateral region, in relation to increasing attentional or working memory demands (Nagahama et al., 1996; Cohen et al., 1997; Courtney et al., 1997). Our results did not illustrate dorsolateral activation; however, comparisons of the DOUBLE condition to the FOCUS and SINGLE conditions showed strong activation within the right inferior frontal gyrus (areas 44 and 47). This area may be involved in the maintenance of information for working memory (Cohen et al., 1997) and has been shown to be transient in nature (Konishi et al., 1998), possibly reflecting the transition between cognitive sets. Konishi et al. (1998) also reported a transient activation in bilateral supramarginal gyrus related to cognitive set shifting. Our results were more anterior; the left inferior parietal (area 40) was active in all contrasts except those comparing the FOCUS condition with either the SINGLE or DOUBLE conditions, where set shifting did not occur.
The parietal cortex has been implicated in attentional tasks as well, but primarily in those involving spatial attentional shift (Corbetta et al., 1993). Our task involved no spatial information because the targets all appeared at the center of the screen. We did find parietal activation within precuneus in contrasts where the DOUBLE or SINGLE conditions were compared with the focused attention conditions. It has been suggested that the precuneus may be active when switching attention between object features (Nagahama et al., 1999), as well as during memory retrieval (Fletcher et al., 1998). The preceding contrasts all involve comparisons of attentional shift.

In sum, our results fail to support the hypothesis that the cerebellum is involved with attentional set shifting. Rather, our results indicate that cerebellar activation is correlated with response reassignment. This function is in accordance with previous theories of cerebellar involvement in motor coordination and timing. The ability to change sensorimotor set in response to contextual stimuli is a necessary element in motor coordination.

\section{REFERENCES}

Akshoomoff NA, Courchesne E (1992) A new role for the cerebellum in cognitive operations. Behav Neurosci 106:731-738.

Albus JS (1971) The theory of cerebellar function. Mathematical Biosciences 10:25-61.

Allen G, Buxton RB, Wong EC, Courchesne E (1997) Attentional activation of the cerebellum independent of motor involvement. Science 275:1940-1943.

Ashburner J, Friston KJ (1999) Nonlinear spatial normalization using basis functions. Hum Brain Mapp 7:254-266.

Berman KF, Ostrem JL, Randolph C, Gold J, Goldberg TE, Coppola R, Carson RE, Herscovitch P, Weinberger DR (1995) Physiological activation of a cortical network during performance of the Wisconsin Card Sorting Test: a positron emission tomography study. Neuropsychologia 33:1027-1046.

Brooks VB, Thach WT (1981) Cerebellar control of posture and movement. In: Handbook of physiology, Section 1, The nervous system, Vol 2, Motor Control, Part 2 (Brooks VB ed), pp 877-946. American Physiological Society: Bethesda, MD.

Brown RG, Marsden CD (1988) Internal versus external cues and the control of attention in Parkinson's disease. Brain 111:323-345.

Cohen JD, Perlstein WM, Braver TS, Nystrom LE, Noll DC, Jonides J, Smith EE (1997) Temporal dynamics of brain activation during a working memory task. Nature 386:604-608.

Corbetta M, Miezin FM, Shulman GL, Petersen SE (1993) A PET study of visuospatial attention. J Neurosci 13:1202-1226.

Courchesne E, Townsend J, Akshoomoff NA, Saitoh O, YeungCourchesne R, Lincoln AJ, James HE, Haas RH, Schreibman L, Lau L (1994) Impairment in shifting attention in autistic and cerebellar patients. Behav Neurosci 108:848-865.

Courtney SM, Ungerleider LG, Keil K, Haxby JV (1997) Transient and sustained activity in a distributed neural system for human working memory. Nature 386:608-611.

Daum I, Schugens MM, Ackermann H, Lutzenberger W, Dichgans J, Birbaumer N (1993) Classical conditioning after cerebellar lesions in humans. Behav Neurosci 107:748-756.

Desmond JE, Fiez JA (1998) Neuroimaging studies of the cerebellum: Language, learning and memory. TICS 2:355-362.

Doya K (1999) What are the computations of the cerebellum, the basal ganglia and the cerebral cortex? Neural Netw 12:961-974.

Fiez JA, Raife EA, Balota DA, Schwarz JP, Raichle ME, Petersen SE (1996) A positron emission tomography study of the short-term maintenance of verbal information. J Neurosci 16:808-822.

Fletcher PC, Shallice T, Frith CD, Frackowiak RS, Dolan RJ (1998) The functional roles of prefrontal cortex in episodic memory. II Retrieval. Brain 121:1249-1256.

Friston KJ, Holmes AP, Worsley KJ, Poline J-B, Frith CD, Frackowiak RSJ (1995) Statistical parametric maps in functional imaging: a general linear approach. Hum Brain Mapp 2:189-210.

Friston KJ, Holmes AP, Worsley KJ (1999) How many subjects constitute a study? NeuroImage 10:1-5.

Gao J-H, Parsons LM, Bower JM, Xiong J, Li J, Fox PT (1996) Cerebellum implicated in sensory acquisition and discrimination rather than motor control. Science 272:545-547.

Grodd W, Hulsmann E, Lotze M, Wildgruber D, Erb M (2001) Sensorimotor mapping of the human cerebellum: fMRI evidence of somatotopic organization. Hum Brain Mapp 13:55-73.

Hayes AE, Davidson MC, Keele SW, Rafal RD (1998) Toward a functional analysis of the basal ganglia. J Cogn Neurosci 10:178-198. 
Ito M (1984) The cerebellum and neural control. New York: Raven.

Ivry R, Keele S (1989) Timing functions of the cerebellum. J Cogn Neurosci 1:136-152.

Kawato M (1999) Internal models for motor control and trajectory planning. Curr Opin Neurobiol 9:718-727.

Konishi S, Nakajima K, Uchida I, Kameyama M, Nakahara K, Sekihara K, Miyashita Y (1998) Transient activation of inferior prefrontal cortex during cognitive set shifting. Nat Neurosci 1:80-84.

Kurata K, Wise SP (1988) Premotor cortex of rhesus monkeys: Setrelated activity during two conditional motor tasks. Exp Brain Res 69:327-343.

Kwong KK, Belliveau JW, Chesler DA, Goldberg IE, Weisskoff RM, Poncelet BP, Kennedy DN, Hoppel BE, Cohen MS, Turner R, Cheng HM, Brady TJ, Rosen BR (1992) Dynamic magnetic resonance imaging of human brain activity during primary sensory stimulation. Proc Natl Acad Sci USA 89:5675-5679.

Le TH, Pardo JV, Hu X (1998) 4 T-fMRI study of nonspatial shifting of selective attention: cerebellar and parietal contributions. J Neurophysiol 79:1535-1548.

Mangels JA, Ivry RB, Shimizu N (1998) Dissociable contributions of the prefrontal and neocerebellar cortex to time perception. Brain Res Cogn Brain Res 7:15-39.

Middleton FA, Strick PL (1997) Dentate output channels: motor and cognitive components. Prog Brain Res 114:553-566.

Middleton FA, Strick PL (2000) Basal ganglia and cerebellar loops: Motor and cognitive circuits. Brain Res Brain Res Rev 31:236-250.

Middleton FA, Strick PL (2001) Cerebellar projections to the prefrontal cortex of the primate. J Neurosci 21:700-712.

Nagahama Y, Fukuyama H, Yamauchi H, Matsuzaki S, Konishi J, Shibasaki H, Kimura J (1996) Cerebral activation during performance of a card sorting test. Brain 119:1667-1675.

Nagahama Y, Okada T, Katsumi Y, Hayashi T, Yamauchi H, Sawamoto
N, Toma K, Nakamura K, Hanakawa T, Konishi J, Fukuyama H, Shibasaki H (1999) Transient neural activity in the medial superior frontal gyrus and precuneus time locked with attention shift between object features. NeuroImage 10:193-199.

Ogawa S, Tank DW, Menon R, Ellermann JM, Kim SG, Merkle H, Ugurbil K (1992) Intrinsic signal changes accompanying sensory stimulation: Functional brain mapping with magnetic resonance imaging. Proc Natl Acad Sci USA 89:5951-5955.

Petersen SE, Fox PT, Posner MI, Mintun M, Raichle ME (1989) Positron emission tomographic studies of the processing of single words. J Cogn Neurosci 1:153-170.

Ravizza SM, Ivry RB (2001) Comparison of the basal ganglia and cerebellum in shifting attention. J Cogn Neurosci 13:285-297.

Rogers RD, Sahakian BJ, Hodges JR, Polkey CE, Kennard C, Robbins TW (1998) Dissociating executive mechanisms of task control following frontal lobe damage and Parkinson's disease. Brain 121:815-842.

Schmahmann JD, Pandya DN (1997a) Anatomic organization of the basilar pontine projections from prefrontal cortices in rhesus monkey. J Neurosci 17:438-458.

Schmahmann JD, Pandya DN (1997b) The cerebrocerebellar system. Int Rev Neurobiol 41:31-60.

Talairach J, Tournoux P (1988) Co-planar stereotaxic atlas of the brain. New York: Thieme.

Thach WT (1997) Context-responsive linkage. Int Rev Neurobiol 41: 599-611.

Wolpert DM, Ghahramani Z (2000) Computational principles of movement neuroscience. Nat Neurosci [Suppl]3:1212-1217.

Wolpert DM, Kawato M (1998) Multiple paired forward and inverse models for motor control. Neural Netw 11:1317-1329.

Yamaguchi S, Tsuchiya H, Kobayashi S (1998) Visuospatial attention shift and motor responses in cerebellar disorders. J Cogn Neurosci 10:95-107. 